\title{
Ausência de diarréia em eqüídeos medicados com oxitetraciclina
}

\section{Absence of diarrhoea in equidae treated with oxytetracycline}

\author{
Márcio Carvalho da Costa ${ }^{1}$; Allan Jürgen Isernhagen ${ }^{1}$; Fábio Lucas Zito de \\ Moraes $^{1}$; Antonio Cezar de Oliveira Dearo ${ }^{2}$; Peter Reichmann ${ }^{2}$; \\ Augusto José Savioli de Almeida Sampaio²; Júlio Augusto Naylor Lisbôa ${ }^{2 *}$
}

\begin{abstract}
Resumo
Foram avaliados e acompanhados 24 eqüídeos medicados com cloridrato de oxitetraciclina, fármaco incriminado como potencial causador de colite severa com manifestação de diarréia nesta espécie. Os eqüídeos estudados eram portadores naturais de afecções que requeriam o emprego de antimicrobianos. Administraram-se doses de 7,15 ou $20 \mathrm{mg} / \mathrm{kg}$, a cada 24 horas, por via intravenosa, durante 4 a até 19 dias seguidos. Não se observou qualquer efeito colateral aparente durante o período de tratamento e após o seu término. A oxitetraciclina mostrou-se, portanto, segura para os eqüídeos, nas doses e intervalo entre doses utilizados.
\end{abstract}

Palavras-chave: Eqüídeos, oxitetraciclina, diarréia.

\begin{abstract}
Evaluation and observation was carried out with 24 equidae put on oxytetracycline hydrochloride medication, a drug incriminated as potential cause of severe colitis with diarrhea manifestations for this species. The animals of this study were natural carriers of affections that required antimicrobial use. During 4 to 19 uninterrupted days intravenous doses of 7,15 or $20 \mathrm{mg} / \mathrm{kg}$ were administered, every 24 hours. No side effects were observed during the period of treatment or after it. Thus, at the doses and intervals described above, oxytetracycline showed to be safe for equidae.
\end{abstract}

Key words: Equidae, oxytetracycline, diarrhoea.

A oxitetraciclina é um fármaco rotineiramente utilizado para o tratamento de infecções bacterianas nas espécies ruminantes domésticas e apresenta como vantagens espectro amplo de ação antimicrobiana, custo reduzido e a apresentação de formulações de ação prolongada. Nos eqüinos, ao contrário, o seu emprego não é rotineiro em virtude do risco potencial de efeitos colaterais. De fato, desde os relatos de Andersson et al. (1971) e de Cook (1973), que incriminaram a oxitetraciclina como causadora de colite severa e fatal nos eqüinos, o fármaco tem sido geralmente evitado como opção terapêutica. As indicações têm se limitado a situações específicas tais como a erliquiose (PALMER; WHITLOCK; BENSON, 1988; PALMER; BENSON; WHITLOCK, 1992) e as deformidades

\footnotetext{
1 Médico Veterinário; Pós-graduando; Departamento de Clínicas Veterinárias (DCV), Centro de Ciências Agrárias (CCA), Universidade Estadual de Londrina (UEL).

2 Médico Veterinário; Doutor; Professor Adjunto; DCV-CCA-UEL, Campus Universitário, Londrina, PR 86051-990.

* Autor para correspondência-Email: janlisboa@uel.br
} 
flexurais dos membros de potros (LOKAI; MEYER, 1985; MADISON et al., 1994; KASPER et al., 1995). O conceito clássico de que a oxitetraciclina provoca diarréia em eqüinos com grande risco vem há muito se perpetuando (BRUMBAUGH, 1990; REED; BAYLY, 1998). A experiência prática demonstra, contudo, que a veracidade do mesmo pode ser questionada. Este artigo tem por objetivo relatar a ausência de efeitos colaterais aparentes quando da utilização do cloridrato de oxitetraciclina de longa ação (LA) por via parenteral para o tratamento antimicrobiano em eqüídeos portadores de diferentes afecções.

Vinte e quatro eqüídeos (22 eqüinos e 2 muares), entre 1 e 13 anos de idade, portadores naturais de afecções que requeriam medicação antimicrobiana (Tabela 1), foram atendidos e internados, para tratamento e acompanhamento da evolução, no Hospital Veterinário da Universidade Estadual de Londrina. Como complemento às medidas terapêuticas apropriadas para cada caso em específico, os animais estudados foram medicados com o cloridrato de oxitetraciclina, formulação de longa ação (Bivatop 200 - Boehringer Ingelheim do Brasil; ou Tetraciclina/LA SPV - Schering-Plough $\mathrm{SA}$ ), como o princípio ativo antimicrobiano. Doses de 7,15 ou de $20 \mathrm{mg} / \mathrm{kg}$, conforme recomendado (ROBINSON, 2003), foram administradas a cada 24 horas, por via intravenosa. Em virtude do elevado poder de irritação tecidual que a oxitetraciclina possui, a veia jugular da maior parte dos animais estudados foi mantida cateterizada (DEARO; REICHMANN, 2001) durante o período de duração do tratamento com o fármaco. Esse período variou de 4 a 19 dias dependendo da afecção principal e de sua evolução. $\mathrm{O}$ período de internamento se estendeu por, no mínimo, mais seis dias adicionais. Empregando-se os métodos semiológicos tradicionais, exames físicos foram realizados diariamente durante todo o período de internamento para a avaliação do estado geral dos animais e da evolução do quadro.

Nenhum eqüídeo estudado apresentou qualquer alteração clínica que pudesse estar relacionada com o uso da oxitetraciclina durante o período de tratamento, ou mesmo dias após o seu término. Não se observaram alterações das funções vitais ou modificações aparentes na consistência das fezes; e o apetite manteve-se bom. Essas evidências contrariam o conceito clássico de que o risco de diarréia é alto em eqüinos medicados com a oxitetraciclina. Os efeitos adversos sobre a flora microbiana intestinal são esperados tanto com a administração do fármaco por via oral (WHITE; PRIOR, 1982) quanto por via parenteral, em virtude de a excreção biliar representar um dos mecanismos importantes de eliminação da oxitetraciclina (McKELLAR; HORSPOOL, 1995).

Segundo as observações de Andersson et al. (1971), parece lógico admitir que o desequilíbrio da flora microbiana intestinal dependa essencialmente da dose empregada. Eqüinos morreram com diarréia severa após receberem uma única dose de 27 a $40 \mathrm{mg} / \mathrm{kg}$ de oxiteraciclina por via intravenosa. Cook (1973), por sua vez, relatou o problema em cavalos medicados, por 3 dias, com doses muito menores (aproximadamente $4 \mathrm{mg} / \mathrm{kg}$ ), submetidos, contudo, ao estresse operatório sob anestesia geral. A despeito desses primeiros trabalhos, a oxitetraciclina tem sido utilizada com sucesso para o tratamento da erliquiose na dose de $6,6 \mathrm{mg} / \mathrm{kg}$, durante 5 dias (PALMER; WHITLOCK; BENSON, 1988; PALMER; BENSON; WHITLOCK, 1992). E, para a correção de deformidades flexurais nos membros de potros, a dose indicada é $70 \mathrm{mg} / \mathrm{kg}$, em administração única por via intravenosa (LOKAY; MEYER, 1985; MADISON et al., 1994; KASPER et al., 1995).

As doses empregadas nesse estudo objetivavam tratar infecções bacterianas já instaladas, na maioria dos casos (Tabela 1), e variaram entre sete, 15 ou $20 \mathrm{mg} / \mathrm{kg}$. A dose menor foi utilizada nos primeiros eqüinos por uma questão de cautela. Tendo se provado segura, as doses maiores foram experimentadas na seqüência. Os efeitos colaterais não se manifestaram nem mesmo no caso em que a duração do tratamento se prolongou por 19 dias. 
Tabela 1. Relação da espécie, sexo, idade, afecção principal, dose utilizada, período de tratamento e evolução dos eqüídeos medicados com oxitetraciclina.

\begin{tabular}{ccccccc}
\hline Espécie & Sexo & $\begin{array}{c}\text { Idade } \\
\text { (anos) }\end{array}$ & Afecção principal & $\begin{array}{c}\text { Dose } \\
(\mathbf{m g} / \mathbf{k g})\end{array}$ & $\begin{array}{c}\text { Dias de } \\
\text { medicação }\end{array}$ & Evolução \\
\hline Eqüina & $\mathrm{M}$ & 2 & Ferida contaminada & 7 & 6 & Cura \\
Eqüina & $\mathrm{F}$ & 1 & Ferida contaminada & 7 & 4 & Cura \\
Eqüina & $\mathrm{F}$ & 10 & Ferida contaminada & 7 & 6 & Cura \\
Muar & $\mathrm{F}$ & 7 & Tétano & 7 & 11 & Cura \\
Eqüina & $\mathrm{F}$ & 6 & Tétano & 7 & 6 & Eutanásia \\
Eqüina & $\mathrm{F}$ & 7 & Pododermatite séptica & 7 & 5 & Cura \\
Eqüina & $\mathrm{M}$ & - & Laparotomia exploratória & 7 & 4 & Cura \\
Eqüina & $\mathrm{F}$ & - & Ferida contaminada & 15 & 10 & Cura \\
Eqüina & $\mathrm{F}$ & 6 & Ferida contaminada & 15 & 5 & Cura \\
Eqüina & $\mathrm{F}$ & 10 & Ferida contaminada & 15 & 6 & Cura \\
Eqüina & $\mathrm{M}$ & 13 & Funiculite & 15 & 19 & Cura \\
Eqüina & $\mathrm{F}$ & 7 & Leptospirose & 15 & 8 & Cura \\
Eqüina & $\mathrm{F}$ & 6 & Tétano & 15 & 10 & Cura \\
Eqüina & $\mathrm{F}$ & 12 & Abscesso abdominal & 15 & 5 & Cura \\
Eqüina & $\mathrm{M}$ & 3 & Periostite & 15 & 8 & Cura \\
Muar & $\mathrm{F}$ & 10 & Pneumonia & 15 & 10 & Cura \\
Eqüina & $\mathrm{M}$ & 10 & Ferida contaminada & 20 & 4 & Cura \\
Eqüina & $\mathrm{M}$ & 1 & Ferida contaminada & 20 & 6 & Cura \\
Eqüina & $\mathrm{M}$ & - & Ferida contaminada & 20 & 5 & Cura \\
Eqüina & $\mathrm{F}$ & 6 & Ferida com flegmão & 20 & 5 & Eutanásia \\
Eqüina & $\mathrm{F}$ & 6 & Pododermatite séptica & 20 & 6 & Cura \\
Eqüina & $\mathrm{M}$ & 3 & Pododermatite séptica & 20 & 8 & Cura \\
Eqüina & $\mathrm{F}$ & 5 & Endometrite & 20 & 5 & Cura \\
Eqüina & $\mathrm{M}$ & 6 & Pneumonia & 20 & 7 & Cura \\
\hline
\end{tabular}

O custo reduzido do tratamento deve ser destacado como uma vantagem da oxitetraciclina como opção antimicrobiana. A desvantagem é a obrigatoriedade de administração pela via intravenosa. O poder irritativo do fármaco torna-o contra-indicado por via intramuscular e potencialmente danoso ao tecido quando acidentalmente administrado no espaço perivascular. A prescrição do tratamento deve ficar limitada de acordo com a perícia do indivíduo em realizar injeções intravenosas.

Em suma, nas doses e nos intervalos entre doses empregados para o tratamento antimicrobiano em eqüídeos acometidos por diferentes enfermidades, a oxitetraciclina não induziu os efeitos colaterais clássicos relatados repetidamente na literatura. Estudos complementares com número maior de observações poderão reforçar tais evidências.

\section{Referências}

ANDERSSON, G.; EKMAN, L.; MANSSON, I.; PERSSON, S.; RUBARTH, S.; TUFVESSON, G. Lethal complications following administration of oxytetracycline in the horse. Nordic Veterinary Medicine, Copenhagem, v.23, n.1, p.922, jan. 1971.

BRUMBAUGH, G. W. Antimicrobial therapy. In: SMITH, B. P. Large animal internal medicine. St Louis: C.V. Mosby, 1990. p.1436-51.

COOK, W. R. Diarrhoea in the horse associated with stress and tetracycline therapy. Veterinary Record, London, v.93, n.15, p.15-7, jul. 1973. 
DEARO, A. C. O.; REICHMANN, P. Fluidoterapia em grandes animais: quantidade e vias de administração. Revista de Educacao Continuada do CRMV-SP, São Paulo, v.4, n.3, p.3-11, set./dez. 2001.

KASPER, C. A.; CLAYTON,H. M.; WRIGHT, A. K.; SKUBA, E. V.; PETRIE, L. Effects of high doses of oxytetracycline on metacarpophalangeal joint kinematics in neonatal foals. Journal of the American Veterinary Medical Association, Schaumburg, v.207, n.1, p.71-3, jul. 1995.

LOKAI, M. D.; MEYER, R. J. Preliminary observations on oxytetracycline treatment of congenital flexural deformities in foals. Modern Veterinary Practice, Santa Barbara, v.66, p.237-9, 1985.

MADISON, J. B.; GARBER, J. L.; RICE, B.; STUMF, A. J.; ZIMMER, A. E.; OTT, E. A. Effect of oxytetracycline on metacarpophalangeal and distal interphalangeal joint angles in newborn foals. Journal of the American Veterinary Medical Association, Schaumburg, v.204, n.2, p.246-9, jan. 1994.

McKELLAR, Q. A.; HOSPOOL, L. J. I. Stability of penicillin $\mathrm{G}$, ampicillin, amikacin and oxytetracycline and their interactions with food in in vitro simulated equine gastrointestinal contents. Research In Veterinary Science, London, v.58, n.3, p.227-31, may 1995.
PALMER, J. E.; BENSON, C. E.; WHITLOCK R. H. Effect of treatment with oxytetracycline during the acute stages of experimentally induced equine ehrlichial colitis in ponies. American Journal of Veterinary Research, Chicago, v.53, n.12, p.2300-4, dec. 1992.

PALMER, J. E.; WHITLOCK, R. H.; BENSON, C. E. Equine ehrlichial colits: effect of oxytetracycline treatment during the incubation period of Ehrlichia risticii infection in ponies. Journal of the American Veterinary Medical Association, Schaumburg, v.192, n.3, p.343-5, feb. 1988.

REED, S. M.; BAYLY, W. M. Equine internal medicine. Philadelphia: W. B. Saunders Company, 1998. 1092p.

ROBINSON, N. E. Current therapy in equine medicine. 5. ed. Philadelphia: Elsevier Science, 2003. 930p.

WHITE, G.; PRIOR, S. D. Comparative effects of oral administration of trimethoprim/sulphadiazine or oxytetracycline on the faecal flora of horses. Veterinary Record, London, v.111, n.14, p.316-8, oct. 1982. 